\title{
Nitrogen Mustard HN-1
}

National Cancer Institute

\section{Source}

National Cancer Institute. Nitrogen Mustard HN-1. NCI Thesaurus. Code C161523.

A nitrogen mustard vesicant that is a slow-evaporating colorless to yellow oily liquid with

a faint musty or fishy odor. It is absorbed into the body by inhalation, ingestion, eye contact, and skin contact, and is a powerful alkylating agent that binds to and crosslinks DNA, preventing cell duplication. 